\title{
STRONG IDENTITIES AND ENDORSEMENT OF HUMAN RIGHTS: CONFLICTIVE OR COMPLEMENTARY?
}

\author{
J. Ziemes* \\ e-mail: johanna.ziemes@uni-due.de
}

\author{
H. Abs* \\ e-mail: h.j.abs@uni-due.de \\ *Faculty of Educational Sciences \\ University of Duisburg-Essen \\ Essen, Germany
}

\section{ABSTRACT}

In higher education, students are exposed to people with diverse backgrounds and opinions and frequently are challenged to participate in scientific discussions on controversial issues. The article discusses the implications of two theoretical approaches within psychology for the meaning of identity in dealing with diversity. Social and developmental psychologists have opposing views on identity: While the former claim that a strong sense of identity leads to competition for resources, to intolerance, to the devaluation of outgroups and, finally, to conflict, the latter argue that a weak sense of identity leads to totalitarian ideologies and intolerance towards deviating beliefs. We review literature on the implications and effects deriving from social and developmental psychology and integrate them in a model which explains how building a strong sense of identity can promote tolerance and the endorsement of human rights. In particular, we explore the importance of tolerance defined as acting towards one another in a spirit of brotherhood because the devaluation of the 'other' often is seen as the first step towards violence.

Keywords: identities, identity theories, tolerances, human rights,

\section{INTRODUCTION}

In June 2013, the University of Duisburg-Essen gained international media attention when a Muslim student removed a poster and destroyed another in an exhibition, seemingly because of their disrespectful representation of Islam and Muslims. While the mass media saw this as a classic conflict between religious convictions and the freedom of artistic expression, or even as acts of antisemitism (Weinthal 2013), some students, not justifying the act itself, expressed awareness of anti-Islamic tendencies in society today (Mac 2013). As an immediate measure the exhibition was closed (Hummitzsch 2013) and later the student was convicted and fined (epd/lvt 2015). Further on the university invited representatives of several involved groups for 
talks and tried to establish a discourse on academic freedom. The president of the university stated: '[...] the university is a place of tolerance and scientific freedom. At the same time it is the essence of scientific discourses to endure opposing points of views ${ }^{1}$ (Kostka 2013). But to implement this is a growing challenge.

Universities have large and diverse student bodies and students are directly confronted with scientific controversies which may question long held beliefs which are important to their identities. In view of what may be perceived as a maelstrom of new ideas questions arise as to when students learn to accept and tolerate, and perhaps even appreciate, opposing opinions, and whether universities should screen students for these abilities before admission. These questions are very important not just for a university where one in five students has a migration background and diversity is greatly valued, such as the University of Duisburg-Essen (University of Duisburg-Essen 2016), but for all higher education institutions striving for diversity. But even irrespective from the university’s mission the matter of academic freedom, and tolerance of opposing views is crucial for all universities in Germany, where - due to demographic dynamics - the student composition is becoming more and more diverse (Trow 2007)

How can tolerance as 'a key concept in contemporary political theory and practice' (Del Águila 2005) be fostered so that the diversity of identities is seen not as a public nuisance but rather as a public good? UNESCO (1995) defines tolerance as 'respect, acceptance and appreciation of the rich diversity of our world's cultures, our forms of expression and ways of being human’ and demand

[a]ppropriate scientific studies and networking (...) to co-ordinate the international community's response to this global challenge, including analysis by the social sciences of root causes and effective countermeasures, as well as research and monitoring in support of policy-making and standard-setting action by Member States.

When it comes to human rights and tolerance, political and scientific definitions interact and cannot be clearly disentangled because different definitions imply differential calls for action (see e.g. Blum 2010). As we will demonstrate, identity formation is a central construct in the development of tolerance and becomes increasingly important in highly diverse contexts in which own identity-relevant beliefs may be challenged. By reviewing theoretical and empirical research we aim to explore the relationships among identity formation, tolerance, and human rights within contexts of higher education. First, we investigate the interdependence of identity, tolerance, and the endorsement of human rights. Then, we explore the role of psychological concepts of identity in the development of tolerance, distinguishing between two approaches: 
social identity theory (SIT), the focus of which is inducible social identities connected to outgroup devaluation and intergroup violence, and developmental theories of identity (DTI), the focus of which is long-lasting developmental processes connected to well-being, democratic behaviour, and tolerance. Finally, we present the results and integrate them in suggestions for (higher) education.

\section{TOLERANCE AND HUMAN RIGHTS: CONCEPTUAL RELATIONS}

While many, especially Western, theorists argue that individuals can only be the benefactors but not be bound by human rights (e.g. Fremuth 2015), other concepts of human rights, such as those outlined in the African Banjul Charta on Human and Peoples' Rights, include duties of individuals towards the family, society, state, and international community ( $\$ 27$ ACHPR 1981). However, this discourse does not include the responsibility of individuals to endorse and maintain human rights. If we conceptualize human rights as the right to protection against state despotism as well as social and participatory rights, the state as an institution may be unable to provide human rights without establishing an alliance with the citizens and institutions. Lengauer $(2011,4)$ argues that human rights can be violated by any person, in example by physically harming another person. Therefore, individuals can be bound towards the respect, protection, and fulfilment of human rights. Human rights bind all who possess power, and as long as not all ways of force are monopolized by the state, human rights also bind organizations, companies, and individuals to the degree to which they wield power. Power is here understood as the authority to withhold, revoke, or violate protection, provision, or participatory rights.

The even more important line of argumentation includes the notion that individuals, especially in democracies, do not just live in, but make, the state. Following Habermas (1996, 384), we note:

the constitutional state does not represent a finished structure but a delicate and sensitive - above all fallible and revisable - enterprise, whose purpose is to realize the system of rights anew in changing circumstances (...).

From this point of view it is not the state as such, but all citizens who need to uphold human rights and influence the state to do the same. Tolerance can be conceptualized as a personality trait (Belasheva and Petrova 2016). Mummendey and Wenzel (1999) take a psychological approach and define tolerance as 'the acceptance and positive estimation of intergroup differences'. They stress that tolerance is more than the 'endurance of deviation', but contains aspects of appreciation of diversity (see also: Vollhardt 2011).

We choose to use the term 'tolerance' instead of 'acceptance' or 'appreciation of diversity' 
for several reasons. First, we follow the UNESCO's definition of tolerance and its implied political consensus. Second, we follow the scientific discourse on tolerance and its determinants, which includes notions of appreciation of diversity (Mummendey and Wenzel 1999). Third, appreciation of diversity is considered the highest level of tolerance and the ultimate goal for inclusive societies. However, many cognitive processes rely on categorization (Greenwald and Banaji 1995). Therefore, from a psychological point of view, the process of overcoming stereotypes is never-ending and tolerance is needed to narrow the gap between conscious appreciation of diversity and aversive sub-conscious processes (Lai et al. 2014).

Tolerance has a dimension of power: Only the powerful and privileged can be tolerant (Del Águila 2005). Carter (2014) connects individuals’ tolerance with liberal philosophies of inclusion and the refusal of complete rejection of 'others' diverse modalities of worship and lifestyle'. The negative wording of this formulation leaves room for clarification. Essentially, tolerance ends where individuals are traceably harmed or the value of tolerance itself is under attack (Del Águila 2005). Leader (1996) uses tolerance to distinguish democracies from oligarchies: In a democracy basic, equal, and special rights take precedence over decisions of the majority. The state and its citizens must protect the rights of minorities who, in a democracy, legitimate the rule of the government no less than the majority. The African concept of Ubuntu introduces a broader view of the recognition of one another as human and inherently worthy of respect, thereby including and exceeding the concept of tolerance (Mabovula 2011; Metz 2014).

Bennett and Bennett's (2004) proposed a developmental model for systems and individuals which is driven by experience of diversity and shows the development from ethnocentric stages such as denial and defence to ethnorelative stages such as adaptation and integration. While the developmental model of intercultural sensitivity focuses on interracial and intercultural relationships, it is easy to generalize for use with other marginalized groups such as people who are homosexual or have disabilities, whose identity is not bound by ethnicity, even though both arguably can be conceptualized as belonging to a subculture (Cass 1979; Peters 2000).

We propose a similar model which includes a mutual and congeneric relationship between the continuous variable of tolerance and the support for different forms of human rights. In figure one the proposed relationship is illustrated: Tolerance here is conceptualized as a psychological trait and illustrated by the first axis. A zero on this tolerance scale can be interpreted as indifference, the absence of both aversion to and appreciation of diversity. When the majority shows complete intolerance towards marginalized groups, members of those minority groups become dehumanized and violence against them is likely to follow (Moshman 
2011). Slight intolerance by the majority may not interfere with its endorsement of the rights of minority groups to protection; even disliked groups’ right to live can be protected. However, when it comes to the provision of basic needs, or even support of full participation, higher levels of tolerance from the majority is needed; the peak of tolerance can be conceptualized as appreciation of diversity. While the definition of tolerance was already discussed in the previous sections, the proposed interactions need further illustration. The next sections will use psychological theories of identity to demonstrate the importance of identity for tolerance and the endorsements of human rights.

$\underline{\text { Relationship Among Tolerance, Identity, and Endorsement of Human Rights }}$

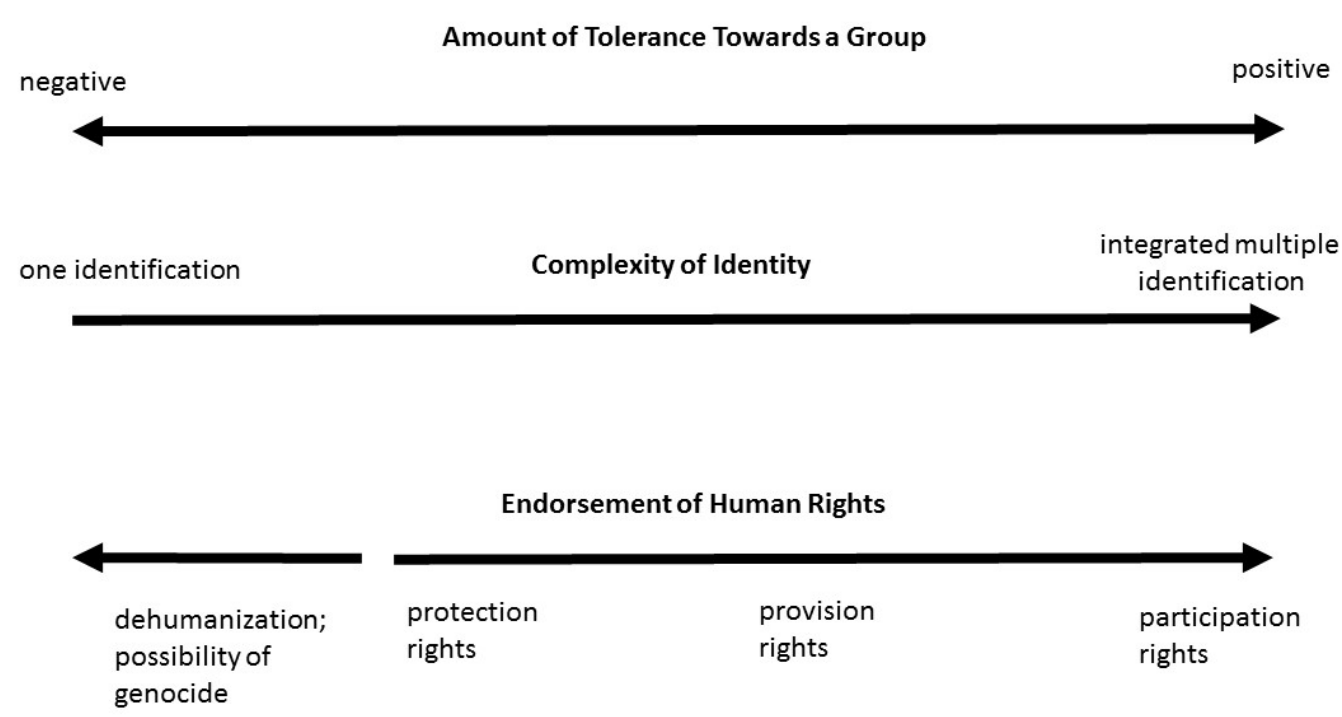

Figure 1: Illustration of the relationship among tolerance, design of identity, and endorsement of human rights.

\section{THE DARK SIDE OF IDENTITY}

After the Second World War when many social psychologists became interested in the effects of conformity, obedience, and group-based violence to find explanations for the Holocaust and for the rise of extreme nationalism in Germany. In his studies on obedience Milgram (1963) was surprised to find that citizens of the United States of America (approximately 65\% of the original sample) would deliver potential deadly electrical shocks to a peer even if disobedience resulted in no punishment or financial loss. More recent research indicates that Milgram's results are still relevant (Burger 2009) and that identification with authority may play an important role in these studies: Participants and aggressors may identify with the administrator and thereby feel a sense of duty towards him or her (Reicher, Haslam and Smith 2012).

How and why do people identify with groups and causes which may cause harm to others? 
Tajfel, often seen as founder of social identity theory (SIT), defined social identity as 'that part of an individual's self-concept which derives from his knowledge of his membership of a social group (or groups) together with the value and emotional significance attached to that membership’ (Tajfel 1978, 63). In this paradigm the individual's self-identification is not necessarily based on profound reasoning but rather can be quite arbitrary: In one study people were randomly assigned to one of two groups but were told that their assignment to a particular group was based on their preference for one of the abstract painters, either Klee or Kandinsky. Surprisingly, this was sufficient to create intergroup discrimination: When asked to determine payoff rules for rewards in intergroup games participants choose payoff patterns which maximized the intergroup difference, rather than maximizing overall profits for both groups (Billig and Tajfel 1973).

In SIT individuals aim to achieve and maintain a positive social identity. Only minimal, arbitrary grouping information is needed to create a sense of in-group and out-group. Groups have salience and valence and the positive notion of a group relies on favourable comparisons to other groups. To enhance their self-esteem people will try to enhance the valence of their group or try to switch the group. Highly valued groups will restrict social mobility to retain meaningful distinctions between themselves and the out-groups; losses are accepted in order to retain inter-group differences (Tajfel and Turner 1979). The ultimate goal within the logic of SIT is to enhance self-esteem by achieving perceived superiority to other groups. Consequently, social identities can be used to explain and predict inter-group violence. One prominent example is the Stanford Prison Experiment, in which participants were randomly assigned to be prisoners or wardens and over multiple days the wardens became increasingly violent towards the other group until finally the experiment needed to be terminated (Haney, Banks and Zimbardo 1973).

In one meta-analysis people were found to be more likely to cooperate with and favour ingroup members in social experiments, and this effect was found to intensify with common knowledge of group memberships and a higher percentage of males in the sample. Surprisingly, there was no difference between the results of studies done with naturally occurring groups and those done with experimentally constructed groups (Balliet, Wu and Dreu 2014). In another meta-analysis in-group bias in natural groups was found to be stronger in collectivistic cultures (Fischer and Derham 2016). Such discussion assumes that in-group favouritism implies discrimination. Although some overlap of these two concepts is obvious (groups do not treat other groups in the same way), further elaboration is needed: While in-group favouritism does not by definition target vulnerable groups, positive tolerance and endorsing human rights is 
especially important for marginalized groups.

Huddy (2001; 2013) reviews the implications of SIT for political psychology: The cohesion of political groups is determined by the individuals' strength of group identification, convergence of identities (the degree to which different identities are seen as harmonizing e.g., nationals who speak the same language and have the same religion), group meaning (some groups are constructed to imply cohesion inherently, such as political parties, while others do not, such as students), similarity to a prototype (an assumed 'average' member of the group), and shared (materialistic or symbolic) interests and threats. Group-based action is determined by the general emotional state of the group (anxiety leads to inaction, while anger leads to action), the degree to which individuals identify with the group (the stronger the identification the more extreme the emotional reaction), group members' perception of the strength of the group (members of strong groups tend to become angry rather than anxious).

Group identities can be strengthened by increasing the salience of the group. In a study of a sample of people from 10 countries in Africa, oncoming elections increased the importance of racial identity, possibly because citizens become conscious about their racial identity when election campaigns promise new allocation of resources (Eifert, Miguel and Posner 2010). Strong identification with a political group is significantly connected to the animalistic dehumanization of the out-group (Pacilli et al. 2016). In the process of dehumanization, the dignity of members of the out-group is disregarded.

Moshman (2007; 2011) elaborates on the process of dehumanization, which eventually leads to genocide. Genocide, in Moshman's opinion, 'is not so much a crime of hate as a crime of identity' (2007), meaning that individuals yield their personal identity to the group identity and therefore no longer feel responsible for their actions by a process of four steps: dichotomization (rendering only one aspect of identity as highly relevant, e.g. German vs. Jewish, Hutu vs. Tutsi, and ignoring overarching identities), dehumanization (promoting a sense of 'natural' superiority often by frequent framing of the 'opposite' group as animals or parasites and denying moral responsibility to those labelled 'subhuman'), destruction (organizing physical violence and murder of a people or destruction of a culture, e.g., separating children from their parents and culture), and denial (selective remembering, rewriting history, ongoing dehumanizing, and victim-blaming). In the final step, memories are consciously and unconsciously adapted to enable a coherent image of oneself as moral a person.

However, experimental research also has revealed that the activation of group-norms of empathy towards others can lead to increased empathy for non-group members (Tarrant, Dazeley and Cottom 2009). In another study of university students from the Netherlands strong 
identification with the state decreased the amount of tolerance towards Muslims. This effect was buffered to non-significance when students believed their state historically was tolerant. Even a short lecture-based intervention on the historical importance of tolerance increased reported tolerance towards Muslims (Smeekes, Verkuyten and Poppe 2012). Although there may be an effect of social desirability, these studies indicate that group norms can enhance tolerance and empathy. Similar results can be reported for Canada, where Canadian identity does not interfere with tolerance or positive attitudes towards multiculturalism (Kalin and Berry 1995). Taken together, even if identity-related processes play an important role in group-based acts of violence, identity itself is not a threat to tolerance or human rights. In the next section the positive connections between identity formation and tolerance are outlined.

\section{THE BRIGHT SIDE OF IDENTITY}

Eric Homburger Erikson (1973) proposed a theory of psychosocial development comprising eight stages from infancy to old age. According to Erikson, identity is the meaningful integration of an individual's experiences with significant others and the greatest danger in psychosocial development is the diffusion of one's identity: not finding a stable identity for oneself but blindly and desperately embracing a single group membership with its values. These values are defended aggressively because group membership is perceived as the only safe haven. If the individual's identity is threatened, totalitarian ideas with clear cuts between friends and foes are more welcome than mutual understanding, and discrimination against groups which are perceived as threatening may ensue (Erikson 1973, 110f).

In the developmental theory of identity (DTI) the strength of one's sense of identity does not determine proneness to group ideologies but rather resistance to totalitarian ideas. Although SIT-based results are related to ascribed identities, SIT is lacking when it comes to describing deliberate choices of acquired identities and their consequences (Huddy 2001). Marcia (1966) formalized this developmental process and proposed two functions of identity: exploration and commitment. He claims the most favourable state of identity achievement is having a stable commitment to the identity while being open to exploration. He points out that unquestioned commitment and limited exploration during the foreclosure stage is connected to authoritarian submission, endorsement of strong leadership, obedience, and respect for authority.

Right-wing authoritarianism can be defined as a psychological trait which describes a person's proneness to submit to authorities 'perceived to be established and legitimate' (Seel 2012). authoritarianism may play a part in sustaining a positive notion of oneself at the cost of minorities (Van Hiel and De Clercq 2009). In a meta-analysis moderate effects of 
authoritarianism and strong effects of a social dominance orientation were found on prejudice (Sibley and Duckitt 2008). Further, authoritarianism has been found to be connected to social dominance orientation, prejudice (Asbrock, Sibley, and Duckitt 2009), and reported readiness for ethnic prosecution (Thomsen, Green, and Sidanius 2008). In a longitudinal study of identity formation in young adults concerns with individuation and identity were found to be one of the strongest negative predictors of authoritarianism (Peterson and Lane 2001).

In this context, DTI work at a more differentiated level than SIT. With DTI it is possible to make assumptions about the connection between social identities and tolerance, for example, that reduction to one identity will lead to less tolerance, while people with multiple strong identities are more tolerant. Complex social identities, which can be defined as identities which integrate the belonging to multiple groups at the same time, are found to be connected to measures of tolerance (Brewer and Pierce 2005) and decreased dehumanization (Prati et al. 2016). Identity conflict has been found to be reduced by attribution complexity, that is, the tendency to look for more complex reasons behind events, further indicating that building complex identities improves well-being and the ability to adapt (Leong and Ward 2000).

Berry (1997) explored the identity formation and well-being of immigrants using two axes of identity: Identification with the majority culture and identification with the minority culture. While identification with neither (marginalization) is the least favourable, the more complex identification with both (integration) is favourable for psychosocial and sociocultural adaptation (Kalin and Berry 1995), giving further evidence that complex identities are preferable for a healthy, tolerant development of individuals and societies.

National identities do not inherently foster intolerance. Superordinate groups, like the United Nations or a Nation State, also have the power to foster support among subordinate groups like countries or regions within a country (Wenzel, Mummendey and Waldzus 2010), as long as one's distinctiveness is not lost (Brewer 1991). In a study of a stratified sample from South Africa linking one's self-esteem with the national identity - not strongly identifying with it - decreased interracial tolerance (Gibson 2006). In a German study the differential functioning of patriotism (conceptualized as critical esteem of the nation) and nationalism (conceptualized as idealization of the nation) was investigated. Both constructs were found to have antagonistic effects on antisemitism and devaluation of foreigners. Patriotism was related positively to tolerance (Blank and Schmidt 2003). Positive group identification is possible at a national level without outgroup devaluation. For example, national identity is used as a unifier in Canada, which has a highly diverse population (Berry 2013).

Although complex identities can be more favourable than simple or dichotomous ones, 
there may be situations in which a phase of strong identification with one group may be favourable: Minorities, such as homosexuals, experience discrimination and may internalize society's negativity and suffer severe psychosocial harm (Meyer 2003). A phase of strong identification may help minorities to overcome internalized stereotypes (Cass 1979). Similar results are to be expected for race (Speight 2007), class (Russell 1996), and gender (Szymanski et al. 2009). Finally, intersections of discrimination regarding people with different configurations of belonging to disadvantaged groups need to be taken into account (Weber 1998).

There are great challenges to forming healthy identities and tolerance, especially in contexts of political violence: Wainryb and Recchia (2015; Wainryb and Pasupathi 2010) review the ways political violence may hinder identity formation. First, polarized group identities are adapted to make sense of the conflict and thereby refuel the very same conflicts and hinder the development of alternative identities. Second, victims of political violence may avoid trying to make sense of the conflicts and become numb to reflections on motivation, emotion, or cognition in times of violence and thereby inhibit the process of meaning making, which forms identity. Third, former victims may try to but fail to make sense of conflicts and consequently adopt an identity of helplessness and aggressive victimhood. ${ }^{2}$ Fourth, if governments direct violence on their protégés, collective identities may be discarded, resulting in a fragmentation and diffusion in general opportunism. Fifth, those drawn into violent acts themselves often must overcome feelings of guilt if they want to build a non-violent identity in times after the conflict, or they may be left with their combatant identity. Finally, refugees are drawn between the need to identify as a prosecuted minority and the pressure from the host culture to assimilate, even if integration allows multiple identity aspects to be present (Wainryb and Pasupathi 2010; Berry 1997).

\section{THE FUTURE OF IDENTITY: INTERVENTIONS AND OUTLOOK}

The aim of this article was to shed light on the connection among human rights, tolerance, and identity. In this final section we relate our considerations more explicitly to the context of higher education. Students do not always share the value of tolerance when they enter a university. We propose a model in which tolerance is an interval-scaled personality trait driven by the development of more complex identities and implying the endorsement of human rights to others. Identity needs to be analysed through the looking glasses of social psychology and developmental psychology: SIT sheds light on questions of exclusion, obedience, and violence; DTI enable perspectives on lifelong personal growth, tolerance, and cooperation. 
Measures to promote the formation of identity in students can be deduced from theory even though many await empirical validation. It should be explored if higher education inherently fosters more complex attributional strategies or if only certain teaching styles do so. The process of exploring identity can be fostered without defining an outcome, especially if one aims to develop complex identities. At the same time, clear constraints regarding verbal and physical violence need to be discussed and formulated within schools, universities, and societies and communicated clearly from the moment of application. As stated above, positions which undermine tolerance and respect for the dignity of others cannot be promoted.

A generally high level of self-determination and intrinsic motivation to regulate racism are connected to tolerance (Legault et al. 2007). Extrinsically motivated tolerance may be an acceptable starting point but should not be the finishing line. Fostering intrinsic motivation to overcome prejudices, which is coherent with students' identities and values, is a preliminary aim, since overall intrinsically motivated higher education students are more likely to value multiculturalism (Duriez 2011) possibly because they are more likely to interpret situations of collaboration with students of a different cultural background compared to their own as cooperation and less likely as rivalry (Sheldon, Sheldon and Osbaldiston 2000). Therefore, lecturers should foster cooperative learning centering development and predefined criteria of success rather than competition and 'grading on a curve' (Linnenbrink 2005).

Marcia (1966) saw identity exploration as the driver of identity formation. Universities should be places where students with different genders, races, religions, classes and intersections thereof can meet and discuss issues from various points of view. Students should be encouraged to organize lectures and debates and be supported in their efforts to do so, and university teachers also can support the diversity of opinions in their seminars. In Germany the Beutelsbach Consensus (Reinhardt 2016) formulates three widely acknowledged principles for education: Prohibition against overwhelming pupils (teachers must not force their opinions on students); treat controversial topics (in politics and science) as controversial; and consider the personal interests of pupils (put students in a position to evaluate their personal interests). These principles also may be used as guidelines by university teachers.

Empiric evidence for these claims can be found in research on the concept of an open classroom climate. This concept includes efforts of teachers to promote the expression of diverse opinions in the classroom and thereby covers the first two principles of the Beutelsbach Consensus. Open classroom climate is tested mostly in school contexts but also should have positive effects with regard to deliberative opinion forming in higher education. Even though an open classroom climate fosters diversity of opinions and thereby multiplies possibilities of 
identification, it does not result in detachment from institutions, but rather a stronger engagement (Campbell 2008).

The university also can aim to support the formation of a superordinate identity as member or fellow of a valuable institution covering the entire diverse student body so that the students understand one another as part of the same group and thereby actively tolerate each other in their remaining diversity. Superordinate identities should be constructed with great care and not in a way which equals the dominant group with the superordinate identity (Vollhardt, Migacheva and Tropp 2008), otherwise tolerance may become a tool of oppression by claiming tolerance for the needs of majority issues only (Marcuse 1973). Moreover, the subordinate identity should be characterized as having altruistic goals such as a shared commitment to protecting human rights.

Minority groups should not be merely tolerated; they should be provided with safe spaces and the means to organize themselves to overcome internalized negativity and combat institutional discrimination. The rise of gender studies is a good example of how groups who have been discriminated against can contribute greatly to academic discourses and academia itself (Boxer 1982). Finally, the mindset of identity as an eternal work in progress should be nourished. Tolerance and human rights need constant support and defence against backlashes, for instance a fall back to former racial identities in times of political crises (Sullivan, Piereson and Marcus 1979).

The next step for future research could involve creating and validating a questionnaire on tolerance as a personality trait instead of as an attitude towards definite groups, so that developmental processes can be assessed and interventions be evaluated. Further, the connections we presented here among tolerance, identity, and the endorsement of human rights, although theoretically plausible, need to be tested empirically. The cited basic research suggests a great potential for interventions which should be verified in further experiments concentrating on fostering identity exploration and autonomous motivation and complex attributional patterns. Laboratory experiments including workshop sessions on identity formation should be researched as well as longitudinal effects of discursive teaching environments on identity formation and tolerance.

As Sen (2007) states, we all have and share many identities worthy of protection. There still is a lot of research to do, and every generation needs to be convinced anew of the value of tolerance. However, 'tolerance allows us to live together peacefully while enjoying our freedoms’ (Del Águila 2005) and so these efforts seem to be worthwhile. 


\section{NOTES}

1. Translation from German to English was done by the authors.

2. See also learned helplessness (Abramson, Seligman and Teasdale 1978).

\section{REFERENCES}

Abramson, L. Y., M. E. Seligman and J. D. Teasdale. 1978. Learned Helplessness in Humans: Critique and reformulation. Journal of Abnormal Psychology 87(1): 49-74.

ACHPR. 1981. African charter on human and peoples' rights: OAU Doc. CAB/LEG/67/3 rev. 5, 21 I.L.M. 58. Banjul.

Asbrock, F., C. G. Sibley and J. Duckitt. 2009. Right-wing authoritarianism and social dominance orientation and the dimensions of generalized prejudice: A longitudinal test. European Journal of Personality: 324-40.

Balliet, D., J. Wu and C. d. Dreu. 2014. Ingroup favoritism in cooperation: A meta-analysis. Psychological Bulletin 140(6): 1556-1581.

Belasheva, I. V. and N. F. Petrova. 2016. Psychological stability of a personality and capability of tolerant interaction as diverse manifestations of tolerance. International Journal of Environmental \& Science Education 11(10): 3367-3384.

Bennett, J. M. and M. J. Bennett. 2004. Developing intercultural sensitivity: An integrative approach to global and domestic diversity. In Handbook of intercultural training, ed. D. Landis, J. M. Bennett and M. J. Bennett. 3rd Edition. Thousand Oaks, Calif: Sage Publications.

Berry, J. W. 1997. Immigration, acculturation, and adaptation. Applied Psychology 46(1): 5-34.

Berry, J. W. 2013. Research on multiculturalism in Canada. International Journal of Intercultural Relations 37(6): 663-75.

Billig, M. and H. Tajfel. 1973. Social categorization and similarity in intergroup behaviour. European Journal of Social Psychology 3(1): 27-52.

Blank, T. and P. Schmidt. 2003. National identity in a United Germany: Nationalism or patriotism? An empirical test with representative data. Political Psychology 24(2): 289-312.

Blum, L. 2010. Secularism, multiculturalism and same-sex marriage: A comment on Brenda Almond's 'Education for tolerance'. Journal of Moral Education 39(2): 145-160.

Boxer, M. J. 1982. The theory and practice of women's studies in the United States. Feminist Theory 7(3): 661-695.

Brewer, M. B. 1991. The social self: On being the same and different at the same time. Personality and Social Psychology Bulletin 17(5): 475-482.

Brewer, M. B. and K. P. Pierce. 2005. Social identity complexity and outgroup tolerance. Personality and Social Psychology Bulletin 31(3c): 428-437.

Burger, J. M. 2009. Replicating Milgram: Would people still obey today? The American Psychologist 64(1): 1-11.

Campbell, D. E. 2008. Voice in the classroom: How an open classroom climate fosters political engagement among adolescents. Political Behavior 30(4): 437-454.

Carter, A. 2014. Tolerance. In Encyclopedia of quality of life and well-being research, ed. A. C. Michalos, 6676-6683. Dordrecht: Springer Netherlands.

Cass, V. C. 1979. Homosexual identity formation: A theoretical model. Journal of Homosexuality 4(3): 219-235.

Del Águila, R. 2005. Tolerance. European Political Science 4(3): 263-272.

Duriez, B. 2011. The social costs of extrinsic relative to intrinsic goal pursuits revisited: The moderating role of general causality orientation. Personality and Individual Differences 50(5): 684-687. 
Eifert, B., E. Miguel and D. N. Posner. 2010. Political competition and ethnic identification in Africa. American Journal of Political Science 54(2): 494-510.

epd/lvt. 2015. Gericht bestätigt Strafe nach Attacke auf Comic-Poster: Nach Eklat um ComicAusstellung an Duisburger Uni. Der Tagesspiegel, March 24. http://www.tagesspiegel.de/ kultur/comics/nach-eklat-um-comic-ausstellung-an-duisburger-uni-gericht-bestaetigt-strafenach-attacke-auf-comic-poster/11552228.html

Erikson, E. H. 1973. Identität und Lebenszyklus: Drei Aufsätze. 1. ed. Suhrkamp-Taschenbuch Wissenschaft 16. Frankfurt am Main: Suhrkamp. Identity and Life Cycle. Three Essays.

Fischer, R. and C. Derham. 2016. Is in-group bias culture-dependent? A meta-analysis across 18 societies. SpringerPlus 5(70) (January). doi:10.1186/540064-015-1663-6

Fremuth, M. L. 2015. Menschenrechte: Grundlagen und Dokumente. Schriftenreihe / Bundeszentrale für Politische Bildung Band 1650. Bonn: Bundeszentrale für Politische Bildung.

Gibson, J. L. 2006. Do strong group identities fuel intolerance? Evidence from the South African case. Political Psychology 27(5): 665-705.

Greenwald, A. G. and Mahzarin R. Banaji. 1995. Implicit social cognition: Attitudes, self-esteem, and stereotypes. Psychological Review 102(1): 4-27.

Habermas, J. 1996. Between facts and norms: Contributions to a discourse theory of law and democracy. Studies in contemporary German social thought. Cambridge, Mass. MIT Press. Jürgen Habermas; translated by William Rehg.

Haney, C., W. C. Banks and P. G. Zimbardo. 1973. Interpersonal dynamics in a simulated prison. International Journal of Criminology and Penology (1): 69-97.

Huddy, L. 2001. From social to political identity: A critical examination of social identity theory. Political Psychology 22(1): 127-56.

Hubby, L. 2013. From group identity to political cohesion. In The Oxford handbook of political psychology, eds. L. Huddy, D. O. Sears and J. S. Levy, 737-73. 2nd Edition. Oxford: Oxford University Press.

Hummitzsch, T. 2013. Ausstellung nach Protest von Muslimen abgebrochen: Comic-Eklat an Uni Duisburg-Essen. Der Tagesspiegel, July 2. http://www.tagesspiegel.de/kultur/comics/comiceklat-an-uni-duisburg-essen-ausstellung-nach-protest-von-muslimen-abgebrochen/8434532.html

Kalin, R. and J. W. Berry. 1995. Ethnic and civic self-identity in Canada: Analyses of 1974 and 1991 National Surveys. Canadian Ethnic Studies 27(2): 1-15.

Kostka, B. H. 2013. Offen miteinander reden: UB-Ausstellung löst Diskussion aus. https://www.unidue.de/de/presse/meldung.php?id=8107

Lai, C. K., M. Marini, S. A. Lehr, C. Cerruti, J. L. Shin, J. A. Joy-Gaba, A. K. Ho et al. 2014. Reducing implicit racial preferences: A comparative investigation of 17 interventions. Journal of Experimental Psychology: General 143(4): 1765-1785.

Leader, S. 1996. Three faces of toleration in a democracy. Journal of Political Philosophy 4(1): 45-67.

Legault, L., I. Green-Demers, P. Grant and J. Chung. 2007. On the self-regulation of implicit and explicit prejudice: A self-determination theory perspective. Personality \& Social Psychology Bulletin 33(5): 732-749.

Lengauer, A. 2011. Drittwirkung von Grundfreiheiten. Vienna: Springer Vienna.

Leong, C. and C. Ward. 2000. Identity conflict in Sojourners. International Journal of Intercultural Relations 24(6): 763-776.

Linnenbrink, E. A. 2005. The dilemma of performance-approach goals: The use of multiple goal contexts to promote students' motivation and learning. Journal of Educational Psychology 97(2): 197-213.

Mabovula, N. N. 2011. The erosion of African communal values: A reappraisal of the African Ubuntu philosophy. Inkanyiso: Journal of Humanities and Social Sciences 3(1): 38-47. 
Mac. 2013. Eine einseitig geführte Debatte. ak[due]ll, July 9. http://akduell.de/2013/07/eine-einseitiggefuhrte-debatte/

Marcia, J. E. 1966. Development and validation of ego-identity status. Journal of Personality and Social Psychology 3(5): 551-558.

Marcuse, G. E. 1973. Repressive Toleranz [Repressive tolerance]. In Kritik der reinen Toleranz, ed. R. P. Wolff, B. Moore and H. Marcuse. German 1., 91-127. 181. Frankfurt am Main: Suhrkamp.

Metz, T. 2014. Ubuntu: The good life. In Encyclopedia of Quality of Life and Well-Being Research, ed. A. C. Michalos, 6761-6765. Dordrecht: Springer Netherlands.

Meyer, I. H. 2003. Prejudice, social stress and mental health in lesbian, gay and bisexual populations: Conceptual issues and research evidence. Psychological Bulletin 129(5): 674-697.

Milgram, S. 1963. Behavioral study of obedience. The Journal of Abnormal and Social Psychology 67(4): 371-378.

Moshman, D. 2007. Us and them: Identity and genocide. Identity 7(2): 115-135.

Moshman, D. 2011. Identity, genocide, and group violence. In Handbook of identity theory and research, ed. S. J. Schwartz, K. Luyckx and V. L. Vignoles, 20: 917-932. New York, NY: Springer New York.

Mummendey, A. and M. Wenzel. 1999. Social discrimination and tolerance in intergroup relations: Reactions to intergroup difference. Personality and Social Psychology Review 3(2): 158-174.

Pacilli, M. G., M. Roccato, S. Pagliaro and S. Russo. 2016. From political opponents to enemies? The role of perceived moral distance in the animalistic dehumanization of the political outgroup. Group Processes \& Intergroup Relations 19(3): 360-373.

Peters, S. 2000. Is there a disability culture? A syncretisation of three possible world views. Disability \& Society 15(4): 583-601.

Peterson, B. E. and M. D. Lane. 2001. Implications of authoritarianism for young adulthood: Longitudinal analysis of college experiences and future goals. Personality and Social Psychology Bulletin 27(6): 678-690.

Prati, F., S. Moscatelli, F. Pratto and M Rubini. 2016. Predicting support for Arabs' autonomy from social dominance: The role of identity complexity and dehumanization. Political Psychology 37(2): 293-301.

Reicher, S. D., S. A. Haslam and J. R. Smith. 2012. Working toward the experimenter: Reconceptualizing obedience within the Milgram paradigm as identification-based followership. Perspectives on Psychological Science 7(4): 315-24.

Reinhardt, S. 2016. 'The Beutlesbach Consensus'. Journal of Social Science Education 15(2): 11-13. doi:10.4119/UNIBI/jsse-v15-i2-1523.

Russell, G. 1996. Internalized classism. Women \& Therapy 18(3-4): 59-71.

Seel, N. M. 2012. Right-wing authoritarianism. In Encyclopedia of the sciences of learning, ed. N. M. Seel, 2866. Boston, MA: Springer US.

Sen, A. K. 2007. Identity and violence: The illusion of destiny. London: Penguin.

Sheldon, K. M., M. S. Sheldon and R. Osbaldiston. 2000. Prosocial values and group assortation: Within an N-Person prisoner's dilemma game. Human Nature 11(4): 387-404.

Sibley, C. G. and J. Duckitt. 2008. Personality and prejudice: A meta-analysis and theoretical review. Personality and Social Psychology Review 12(3): 248-79.

Smeekes, A., M. Verkuyten and E. Poppe. 2012. How a tolerant past affects the present: Historical tolerance and the acceptance of Muslim expressive rights. Personality \& Social Psychology Bulletin 38(11): 1410-1422.

Speight, S. L. 2007. Internalized racism: One more piece of the puzzle. The Counseling Psychologist 35(1): 126-134. 
Sullivan, J. L., J. Piereson and G. E. Marcus. 1979. An alternative conceptualization of political tolerance: Illusory increases 1950s-1970s. American Political Science Review 73(3): 781-194.

Szymanski, D. M., A. Gupta, E. R. Carr and D. Stewart. 2009. Internalized misogyny as a moderator of the link between sexist events and women's psychological distress. Sex Roles 61(1): 101-109.

Tajfel, H. 1978. Social categorization, social identity and social comparison. In Differentiation between social groups: Studies in the social psychology of intergroup relations, ed. H. Tajfel, 61-76. European monographs in social psychology 14. London, New York: Published in cooperation with European Association of Experimental Social Psychology by Academic Press.

Tajfel, H. and J. Turner. 1979. An integrative theory of intergroup conflict. In The Social psychology of intergroup relations, ed. W. G. Austin and S.Worchel, 33-47. Monterey, CA: Brooks/Cole.

Tarrant, M., S. Dazeley and T. Cottom. 2009. Social categorization and empathy for outgroup members. The British Journal of Social Psychology 48(3): 427-46.

Thomsen, L., E. G. Green and J Sidanius. 2008. We will hunt them down: How social dominance orientation and right-wing authoritarianism fuel ethnic persecution of immigrants in fundamentally different ways. Journal of Experimental Social Psychology 44(6): 1455-1464.

Trow, M. 2007. Reflections on the transition from elite to mass to universal access: Forms and phases of higher education in modern societies since WWII. In International handbook of higher education, ed. J. J. F. Forest and P.G. Altbach, 243-280. Springer International Handbooks of Education. New York: Springer.

UNESCO. 1995. Declaration of principles on tolerance. Paris.

University of Duisburg-Essen. 2016. Daten und Fakten: Data and facts. https://www.uni-due.de/ imperia/md/content/dokumente/datenundfakten/daten_und_fakten.pdf

Van Hiel, A. and B. de Clercq. 2009. Authoritarianism is good for you: Right-wing authoritarianism as a buffering factor for mental distress. European Journal of Personality 23(1): 33-50.

Vollhardt, J. K., K. Migacheva and L. R. Tropp. 2008. Social cohesion and tolerance for group differences. In Handbook on building cultures of peace, ed. J. de Rivera, 139-52. Peace Psychology Book Series. New York: Springer.

Vollhardt, J. R. 2011. Tolerance for diverse groups. In The Encyclopedia of peace psychology, ed. D. J. Christie. Oxford, UK: Blackwell Publishing Ltd.

Wainryb, C. and M. Pasupathi. 2010. Political violence and disruptions in the development of moral agency. Child Development Perspectives 4(1): 48-54.

Wainryb, C. and H. Recchia. 2015. Youths' constructions of meanings about experiences with political conflict: Implications for processes of identity development. In The Oxford handbook of identity development, ed. K. C. McLean and M. U. Syed. Oxford Library of Psychology. New York, NY: Oxford University Press.

Weber, L. 1998. A conceptual framework for understanding race, class, gender, and sexuality. Psychology of Women Quarterly 22(1): 13-32.

Weinthal, B. 2013. Muslim student in Germany destroys Israeli exhibit. Jerusalem Post, July 6. http://www.jpost.com/Jewish-World/Jewish-News/Muslim-student-in-Germany-destroys-Israeliexhibit-318961

Wenzel, M., A. Mummendey and S. Waldzus. 2010. Superordinate identities and intergroup conflict: The ingroup projection model. European Review of Social Psychology 18(1): 331-72. 